\title{
Presentation and management of pediatric orbital cellulitis
}

\author{
Sergio Fanella MD FRCPC ${ }^{1,2}$, Alex Singer MB BCh BAO CCFP 3 , Joanne Embree MD FRCPC ${ }^{1,2}$
}

\begin{abstract}
S Fanella, A Singer, J Embree. Presentation and management of pediatric orbital cellulitis. Can J Infect Dis Med Microbiol 2011;22(3):97-100.
\end{abstract}

BACKGROUND: Orbital cellulitis is a serious, vision-threatening infection.

OBJECTIVE: To review the epidemiology and clinical data of pediatric orbital cellulitis in Manitoba.

METHODS: A 12-year retrospective review was conducted of all children (younger than 18 years of age) with orbital cellulitis admitted to Manitoba's only tertiary pediatric centre. Admission rates for orbital cellulitis were compared over three distinct time periods, based on licensure and funding levels of the heptavalent pneumococcal conjugate vaccine (PCV7) in Manitoba.

RESULTS: Thirty-eight patients with orbital cellulitis were identified. Of these, $11 \%$ were of Aboriginal ethnicity in contrast with $30 \%$ to $40 \%$ of children who were admitted for other respiratory illnesses. Subperiosteal abscesses occurred in 31.5\%. Only eight patients (21\%) required surgery. Follow-up imaging after presentation usually did not indicate a need for subsequent surgical drainage. The mean number of orbital cellulitis cases per 1000 admissions for the following periods before PCV7 licensure, after licensure and before full provincial funding, and after licensure and full funding - were 0.39, 0.53 and 0.90, respectively. No significant difference was noted among any of the periods as PCV7 coverage increased.

CONCLUSIONS: The rate of subperiosteal abscesses was lower than other reports. This may be due to the median age at presentation. In contrast to admissions for most other respiratory infections at the Winnipeg Children's Hospital (Winnipeg, Manitoba), Aboriginal ethnicity was uncommon. Surprisingly, rates of admissions for orbital cellulitis appeared to show an increasing trend with increasing access to PCV7 in Manitoba, although overall the number of cases was very small. Studies into the changing microbiology of orbital cellulitis and sinusitis are warranted.

Key Words: Abscess; Conjugate pneumococcal vaccine; Orbital cellulitis

\section{La présentation et la prise en charge de la cellulite orbitaire pédiatrique}

HISTORIQUE : La cellulite orbitaire est une infection grave qui met en jeu le pronostic visuel.

OBJECTIF : Analyser l'épidémiologie et les données cliniques de la cellulite orbitaire pédiatrique au Manitoba.

MÉTHODOLOGIE : Les chercheurs ont procédé à une analyse rétrospective de tous les enfants (de moins de 18 ans) atteints d'une cellulite orbitaire ayant été admis au seul centre pédiatrique tertiaire du Manitoba pendant une période de 12 ans. Ils ont comparé le taux d'admission imputable à une cellulite orbitaire pendant trois périodes distinctes, selon l'homologation et le taux de financement du vaccin antipneumococcique heptavalent conjugué (Pneumo-C-7) au Manitoba.

RÉSULTATS : Les chercheurs ont repéré 38 patients atteints de cellulite orbitaire. De ce nombre, $11 \%$ étaient d'origine autochtone, comparativement à entre $30 \%$ et $40 \%$ des enfants hospitalisés en raison d'une autre maladie respiratoire. Les chercheurs ont observé des abcès souspériostés dans 31,5\% des cas. Seulement huit patients (21\%) ont dû se faire opérer. En général, l'imagerie de suivi après la présentation n'indiquait pas la nécessité d'un drainage chirurgical. Le nombre moyen de cas de cellulite orbitaire sur 1000 hospitalisations pendant les périodes suivantes : avant l'homologation, après l'homologation et avant le financement provincial complet du Pneumo-C-7, s'élevait à $0,39,0,53$ et 0,90 , respectivement. On n'a remarqué aucune différence significative entre les périodes à mesure que la couverture du Pneumo-C-7 augmentait.

CONCLUSIONS : Le taux d'abcès sous-périostés était plus faible que les autres rapports. Ce peut être attribuable à l'âge médian à la présentation. Contrairement aux hospitalisations imputables à la plupart des autres infections respiratoires au Winnipeg Children's Hospital (Winnipeg, Manitoba), l'origine autochtone n'était pas courante. Fait surprenant, le taux d'hospitalisation attribuable à la cellulite orbitaire semble présenter une tendance croissante à mesure qu'augmente l'accès au Pneumo-C-7 au Manitoba, même si le nombre total de cas était très peu élevé. Des études sur l'évolution de la microbiologie de la cellulite et de la sinusite orbitaires s'imposent.
$\mathrm{O}^{+}$ rbital cellulitis is an invasive bacterial infection of the postseptal tissues of the eye (1). The most common underlying factor for its development is a preceding ethmoid sinusitis, which is in contrast to preseptal (periorbital) cellulitis, in which trauma or bacteremia are the most common predisposing causes. Failure to diagnose and treat orbital cellulitis or abscess has the potential for serious complications that include vision loss, thrombosis, meningitis and intracranial infection (2). The microbiology of orbital cellulitis and abscess tends to reflect the underlying sinus involvement and pathology. Organisms most commonly involved include Streptococcus pneumoniae, Moraxella catarrhalis, Haemophilus species, Staphylococcus aureus, group A streptococcus and upper respiratory tract anaerobes (1-4). The relative contribution of each of these organisms varies among studies; however, S pneumoniae was isolated from $13 \%$ of sinus/abscess specimens in a recent study (5). Blood cultures are infrequently positive, with definitive microbiology obtained from abscess fluid. Introduction of immunization against Haemophilus influenzae type B (Hib) has been associated with a decline in the rates of periorbital and orbital cellulitis (6).

The heptavalent pneumococcal conjugate vaccine (PCV7) was licensed for use in the United States in 2000, and in Canada in 2001 (7). Full-level funding of PCV7 in the provincial vaccine program in Manitoba did not occur until late 2004, although some children did receive the immunization before the institution of the publicly funded program. The introduction of the immunization program included a catch-up program for older infants up to 18 months of age at the time of implementation. In 2008, it was reported that only $69.6 \%$ of twoyear-old children in Manitoba were fully immunized (8). Overall, rates of invasive pneumococcal disease have decreased significantly since the introduction of PCV7 (9) including reduced rates of disease

\footnotetext{
${ }^{1}$ Section of Infectious Disease, Department of Pediatrics; ${ }^{2}$ Department of Medical Microbiology; ${ }^{3}$ Department of Family Medicine, University of Manitoba, Winnipeg, Manitoba

Correspondence: Dr Sergio Fanella, Department of Medical Microbiology, University of Manitoba, Room 530B, Basic Medical Sciences Building,

745 Bannatyne Avenue, Winnipeg, Manitoba R3E 0J9. Telephone 204-789-3619, fax 204-789-3926, e-mail umfanell@cc.umanitoba.ca
} 


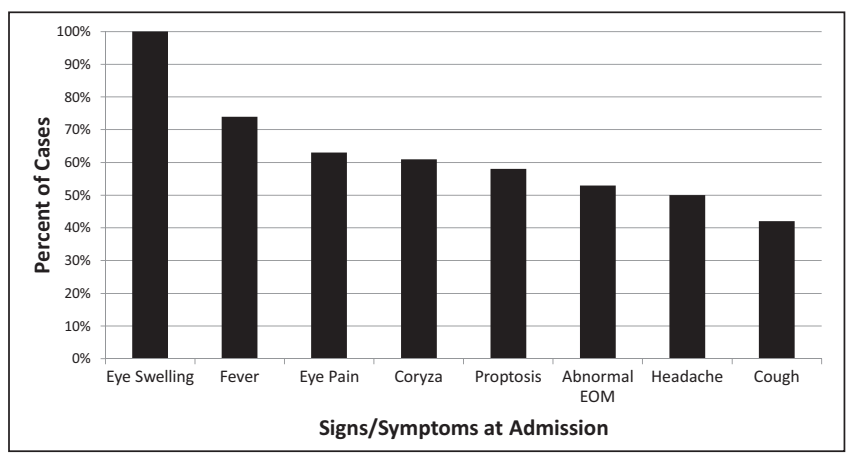

Figure 1) Common presenting signs and symptoms at admission for 38 patients with pediatric orbital cellulitis (1997 to 2008). EOM Extraocular movements

among older populations who were not themselves immunized due to the vaccine's effect on colonization rates and asymptomatic spread throughout the population. This has been observed in pediatric studies in Canada including western provinces (10). However, there has also been an increase in some conditions related to the increased prevalence of pathogenic pneumococcal strains not included in PCV7. Therefore, it is of interest to determine whether the introduction of PCV7 would affect the incidence of orbital cellulitis.

The primary aim of the present study was to review the epidemiology, clinical aspects and management of orbital cellulitis at a Canadian pediatric teaching hospital. In addition, the review provided an opportunity to assess the impact of the publicly funded PCV7 immunization program on the number and presentation of hospitalized cases of pediatric orbital cellulitis in the province of Manitoba.

\section{METHODS}

The present retrospective review included all children (younger than 18 years of age) with a diagnosis of orbital cellulitis admitted to Winnipeg Children's Hospital (WCH) from January 1, 1997, to December 31, 2008. WCH is the only major tertiary care centre for pediatrics for the provinces of Manitoba, eastern Saskatchewan, northwestern Ontario and southern Nunavut, with a total catchment population of more than 1.2 million people. It is the only tertiary care provider for children with serious ophthalmological conditions. The facility contains 114 inpatient beds, with two medical, one surgical and one transplant/immunocompromised ward, and both pediatric and neonatal intensive care units.

Cases were identified through a database search of medical records using the International Classification of Diseases - Ninth and Tenth Revision codes (376.01, H05.0) for orbital cellulitis, as well as a review of the pediatric infectious diseases consultant service database. Only cases confirmed by computed tomography (CT) scans or intraoperative findings were included. Variables reviewed from the medical records include patient demographics (age, sex and community of origin), length of stay, previous medical conditions, symptoms and physical examination findings at presentation, results of investigations (complete blood counts, sterile site cultures and imaging results), number and results of follow-up imaging tests, antimicrobial use, consultation with subspecialists (in the areas of infectious diseases, ophthalmology and otolaryngology), admission to the intensive care unit and surgical interventions. The total number of annual hospital admissions for all causes for the same time period was obtained from a review of the hospital's Infection Prevention and Control database. The proportion of total pediatric patients admitted who are of Aboriginal ethnicity is not routinely recorded, but is, in some circumstances, related to cases of specific diseases (eg, respiratory syncytial virus). Statistical analysis was conducted using Microsoft Excel 2007 (Microsoft Corporation, USA), with $\mathrm{P}<0.05$ considered to be significant. The study was approved by the Bannatyne Campus research ethics board of the University of Manitoba.

\section{RESULTS}

During the study period, 247 children were identified. Of these, 206 had periorbital cellulitis; two had suspected orbital cellulitis, but had no CT scan or other imaging performed; one had infection associated with a prosthetic eyeball and 38 had orbital cellulitis confirmed via CT scan - all children were included in the study. The mean ( \pm SD) number of annual total hospital admissions during the study period was $5268.7 \pm 301.2$.

From the 38 cases, the male to female ratio was 2.2. The mean age was 7.5 years, with a range of one to 16 years. The average number of cases per year was $3.2 \pm 2.0$ (range zero to seven). Presentation was in the fall (September to November) or winter (December to February) for 25 (66\%) cases, while 13 (34\%) presented in the spring (March to May) or summer (June to August). There was no significant difference in seasonal presentation of cases in younger children (nine years of age or younger) compared with older children (older than nine years of age) $(\mathrm{P}=0.15)$. Ethnicity was specified in $94.7 \%$ of cases. Only four $(11 \%)$ of these specified cases were of Aboriginal or Inuit ethnicity, and the remainder were Caucasian. Thirteen (34\%) cases were from communities outside of Winnipeg. Asthma was the most common underlying medical condition seen in four cases; three patients had an underlying history of chronic sinusitis, and two had a history of recent dental infections.

The frequencies of common presenting symptoms and signs are outlined in Figure 1. All cases had unilateral disease. The left eye was involved in 25 (66\%) cases. Ethmoid sinusitis was noted in 36 (94.7\%) cases, and pansinusitis was noted in six children (15.7\%). The mean duration of symptoms before admission was $4.4 \pm 4.4$ days (range one to 21 days). Antimicrobials before admission were used in 22 (58\%) cases, for a mean duration of $2.5 \pm 2.4$ days (range one to 10 days). Oral amoxicillin was used in $12(32 \%)$ cases. There was no difference in fever at presentation related to the receipt of previous antibiotics $(\mathrm{P}=0.71)$.

Baseline investigations included a mean white blood cell count of $13.4 \pm 4.5 \times 10^{9} / \mathrm{L}$ (range $6.3 \times 10^{9} / \mathrm{L}$ to $27.8 \times 10^{9} / \mathrm{L}$ ), with $25(67 \%)$ cases falling within the normal range $\left(5 \times 10^{9} / \mathrm{L}\right.$ to $\left.15 \times 10^{9} / \mathrm{L}\right)$, and an erythrocyte sedimentation rate of $61.0 \pm 29.6 \mathrm{~mm} / \mathrm{h}$, with only one of 12 cases with a rate lower than $20 \mathrm{~mm} / \mathrm{h}$. All but six patients had blood cultures sent at admission. Only one blood culture was positive $(3.1 \%)$ for Streptococcus pyogenes. Intraoperative cultures of abscesses were obtained in eight cases, following zero to nine days of antibiotic therapy. Three cultures were sterile, while two cases had positive Gram stains (Gramnegative bacilli and Gram-positive cocci) with negative cultures. Organisms recovered were one each of methicillin-susceptible $S$ aureus, viridans group Streptococcus and S pyogenes. Of the 22 children who had received antibiotics before admission, only two had positive cultures. Of the eight operative cases, five had previously received antibiotics; three of those five had sterile or negative intraoperative cultures.

CT scans at admission revealed subperiosteal abscesses in 12 children $(31.5 \%)$, with a mean diameter of $1.4 \pm 0.5 \mathrm{~cm}$ (largest abscess was $2.3 \mathrm{~cm}$ in diameter). There were four cases of additional orbital abscesses (two involving medial rectus muscles, one postseptal fluid collection and one orbital abscess). Four children had immediate surgical drainage based on findings of the initial CT scan. Eleven cases had repeat CT scans to measure response to initial intravenous antibiotic therapy without drainage; four cases $(36.4 \%)$ then required surgical drainage. Overall, eight cases $(21 \%)$ required surgical intervention. The mean duration of illness before hospitalization did not differ significantly between those with or without surgical intervention (6.1 days versus 3.9 days $[\mathrm{P}=0.21])$. Patients who underwent surgery were significantly older than those treated medically (10.6 years versus 6.6 years $[\mathrm{P}=0.02])$. Involvement of subspecialties included ophthalmology (81\%), otolaryngology (79\%), infectious diseases $(45 \%)$ and all three services in $39 \%$ of cases.

Intravenous antibiotics were used in all patients at hospital admission (Table 1). Initial antibiotics were changed in 12 (32\%) cases, on average, after $2.3 \pm 2.0$ days, based on infectious diseases consultations 
TABLE 1

Combinations of intravenous (IV) antibiotics used at admission on 38 cases of orbital cellulitis

\begin{tabular}{lc}
\hline IV antibiotic used & Cases, $\mathbf{n}(\%)$ \\
\hline IV cefuroxime & $9(24)$ \\
IV clindamycin + IV cephalosporin & $8(21)$ \\
IV cloxacillin + IV cefotaxime & $8(21)$ \\
IV cefotaxime & $7(18)$ \\
Other IV antibiotics & $\mathbf{6}(16)$ \\
\hline Vancomycin + cefotaxime & $2(5)$ \\
Cefuroxime + metronidazole & $2(5)$ \\
Penicillin & $1(3)$ \\
Ampicillin + cefuroxime & $1(3)$ \\
\hline
\end{tabular}

in $75 \%$ of cases. This generally involved either changing from a second- to a third-generation cephalosporin or the addition of clindamycin. Data on stepdown and total duration of therapy were available in all but one case. Amoxicillin plus clavulanic acid was the most commonly used oral therapy $(40 \%)$, followed by oral cefuroxime (13\%). The total duration of antibiotic therapy was $18.7 \pm 6.5$ days. The mean length of hospital stay was $7.0 \pm 2.7$ days (range three to 14 days). Only one patient required admission to the intensive care unit. There were no deaths, and no patients required readmission within 30 days of discharge.

The mean number of cases per 1000 admissions per year at WCH for the four-year periods based on the status of PCV7 availability and funding are outlined in Figure 2. There were no significant differences among any of the time periods (before PCV7 licensure versus after licensure but before full provincial funding, $\mathrm{P}=0.53$; after licensure before full funding versus after licensure and full funding, $\mathrm{P}=0.25$; and before $\mathrm{PCV} 7$ licensure versus after full funding, $\mathrm{P}=0.20$ ).

\section{DISCUSSION}

The present retrospective study examined clinical presentation, imaging results and interventions of hospitalized children with orbital cellulitis from Manitoba's only pediatric tertiary care centre.

Surprisingly, Aboriginal children comprised a very small percentage of cases despite the demographics of our patient population. Our catchment area serves a large Aboriginal and First Nations population, and this is reflected in the spectrum of all admissions to our centre, especially in the area of respiratory-related infections, which generally comprise a sizable proportion of annual acute hospital admissions for acute respiratory disease. In general, $30 \%$ to $40 \%$ of admissions for respiratory syncytial virus involve Aboriginal children (personal communication, K Olekson, WCH Infection Control) in contrast to the $11 \%$ of the cases with orbital cellulitis. We are not aware of any data suggesting that prevalence of sinusitis is lower in Aboriginals compared with other ethnic groups, and this warrants further study of both epidemiology and immune response.

In contrast to the anticipated decline in cases with the use of PCV7, the number of admissions for orbital cellulitis at WCH actually appeared to increase over time with increasing availability and use of PCV7, although this was not significant, and overall involved a rare condition. Previous studies have demonstrated decreasing incidence of invasive pneumococcal disease following the widespread use of PCV7 in children during an equivalent time period (9-11). Our initial hypothesis was that as PCV7 became more accessible in Manitoba, the rate of admission for orbital cellulitis would decrease over time because the microbiology of orbital cellulitis is believed to reflect that of underlying sinusitis, of which $S$ pneumoniae is a part $(12,13)$. The lack of significant decrease was surprising. This could be due to changes or replacement in the predominant colonizing serotypes of pneumococcus. The phenomenon of serotype replacement of S pneumoniae for both colonizing and invasive isolates has been well described $(14,15)$. Also, general changes in underlying sinus flora could have changed over time, possibly with organisms - such as S aureus or S pyogenes - becoming more prevalent.

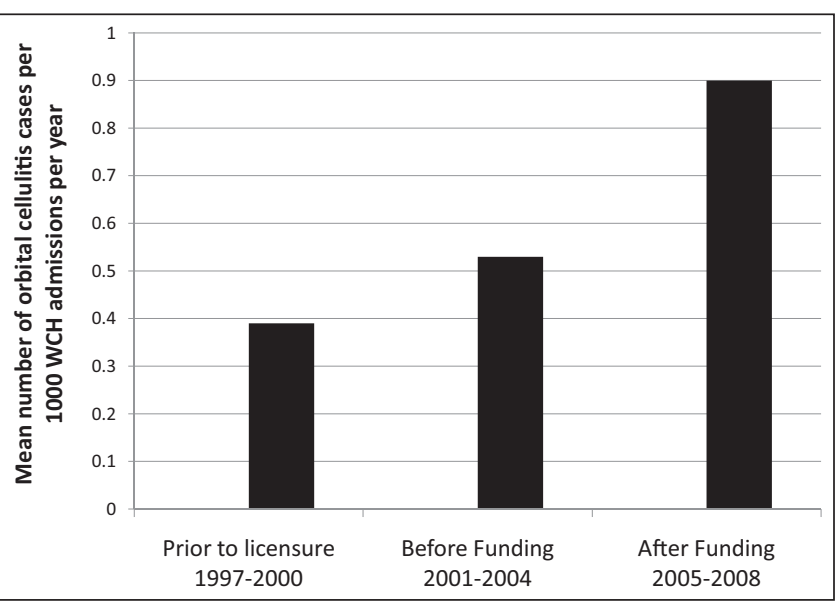

Figure 2) The mean number of cases per 1000 admissions per year in four-year periods from 1997 to 2008, based on the status of heptavalent pneumococcal conjugate vaccine (PCV7) in Manitoba. WCH Winnipeg Children's Hospital, Manitoba

Good clinical outcomes and generally infrequent use of antibiotics with activity versus methicillin-resistant $S$ aureus suggests that methicillinresistant $S$ aureus is not currently a major causative organism in pediatric orbital cellulitis in Manitoba. Vaccination has influenced the presentation of orbital cellulitis in the past, with significantly lower rates following widespread use of Hib immunization (6). However, in one study of military-dependent children over a 25-year period (16), no significant changes were noted in disease burden of orbital and facial cellulitis following introductions of Hib and PCV7 vaccines. This study was limited to children younger than seven years of age.

The distribution and mean age of our group ( $7.5 \pm 4.5$ years), as well as male predominance, were in keeping with results reported by other studies $(12,17,18)$. However, some series have reported different involved age groups, with some having a predominant number of cases younger than two years of age (4) and others with a mean of 12 years of age (19). Ethnicity, local referral and practice patterns could be possible explanations for these differences, but perhaps reflects differences in the prevalence of underlying medical conditions or in the predominant respiratory microbiology in the regions. When to initiate surgical intervention in orbital cellulitis has been debated, but factors that are generally considered include older age (eight years of age or older), large abscesses (greater than $1 \mathrm{~cm}$ ), higher temperatures at admission $(13,18,20)$, and lack of response to medical therapy alone or concern for optic nerve or retinal compromise. The majority of medically treated cases do well (21). Our rates of subperiosteal abscesses, other abscesses and surgical intervention were notably lower than in other studies $(2,5,12,20,22)$. From our series, only five patients $(13 \%)$ eight years of age or older had abscesses greater than $1 \mathrm{~cm}$ in size; of those, three patients $(60 \%)$ required surgical drainage compared with only $15 \%$ of the remaining 33 patients requiring surgery. This lack of older children with large abscesses likely accounts for our lower surgical rates. Repeat CT scans did not result in surgical intervention in the majority of cases. Further study is required to determine exact criteria supporting repeat imaging, and whether clinical scoring of response or alternative modalities might be useful and effective (magnetic resonance imaging and ultrasound of orbit), thereby lessening radiation exposure.

Limitations of our study include its retrospective design and searching for a relatively uncommon disease. In addition, the immunization status of individual cases could not be confirmed directly because access to the Manitoba Immunization Monitoring System (immunization records derived from manual entry of public health-provided immunizations and physician billing claims) was not part of the present study.

In our review of pediatric orbital cellulitis, the rates of subperiosteal abscesses and the need for surgical drainage were lower than in 
other studies. Surprisingly, few cases were of Aboriginal ethnicity, in contrast to most other respiratory infections at our centre. The lack of response of orbital cellulitis to the introduction of PCV7 in Manitoba could be a reflection of changes in the underlying flora of the upper respiratory tract. This surprising result should be reviewed in other populations, in addition to the microbiology of orbital infections and sinusitis.

FINANCIAL SUPPORT: The authors have no financial disclosures or conflicts of interest to report. SF was supported by a clinical postdoctoral fellowship award from the Manitoba Institute of Child Health (MICH).

\section{REFERENCES}

1. Yen KG, Chilakapati MC, Coats DK, et al. Ocular infectious diseases. In: Feigin RD, Cherry JD, eds. Textbook of Pediatric Infectious Diseases, 6th edn. Philadelphia: Lippincott Williams \& Wilkins; 2009:811-35.

2. McKinley SH, Yen MT, Miller AM, et al. Microbiology of pediatric orbital cellulitis. Am J Ophthalmol 2007;144:497-501.

3. Wald ER. Periorbital and orbital infections. In: Long SS, Pickering LK, Prober CG, eds. Principals and Practice of Pediatric Infectious Diseases, 3rd edn. Philadelphia: Elsevier, 2008:511-6.

4. Starkey CR, Steele RW. Medical management of orbital cellulitis. Pediatric Infect Dis J 2001;20:1002-5.

5. Rudloe TF, Harper MB, Prabhu SP, et al. Acute periorbital infections: Who needs emergent imaging? Pediatrics 2010;125:e719-26.

6. Ambatti BK, Ambati J, Azar N, et al. Periorbital and orbital cellulitis before and after the advent of Haemophilus influenzae type B vaccination. Ophthalmology 2000;107:1450-3.

7. Kellner JD, Church DL, MacDonald J. Progress in the prevention of pneumococcal infection. CMAJ 2005;173:1149-51.

8. Manitoba Child Health Atlas Update. <http://mchp-appserv.cpe. umanitoba.ca/reference/Child_Health_Atlas_Update_Final.pdf> (Accessed on January 26, 2011).

9. Poehling KA, Talbot TR, Griffin MR, et al. Invasive pneumococcal disease among infants before and after introduction of pneumococcal conjugate vaccine. JAMA 2006;295:1668-74.
10. Laupland KB, Gregson DB, Vanderkooi OG, et al. The changing burden of pediatric bloodstream infections in Calgary, Canada, 2000-2006. Pediatr Infect Dis J 2009;28:114-7.

11. Kaplan SL, Mason EO, Wald ER, et al. Decrease of invasive pneumococcal infections in children among 8 children's hospitals in the United States after the introduction of the 7-valent pneumococcal conjugate vaccine. Pediatrics 2004;113:443-9.

12. Naheswaran S, Woods CR, Benjamin DK, et al. Orbital cellulitis in children. Pediatr Infect Dis J 2006;25:695-9.

13. Givner LB. Periorbital versus orbital cellulitis. Pediatr Infect Dis J 2002;21:1157-8.

14. Messina AF, Katz-Gaynor K, Barton T, et al. Impact of pneumococcal conjugate vaccine on serotype distribution and antimicrobial resistance of invasive Streptococcus pneumoniae isolates in Dallas, TX, children from 1999 through 2005. Pediatr Infect Dis J 2007;26:461-7.

15. Pelton SI, Huot H, Finkelstein JA, et al. Emergence of 19A as virulent and multidrug resistant pneumococcus in Massachusetts following universal immunization of infants with pneumococcal conjugate vaccine. Pediatr Infect Dis J 2007;26:468-72.

16. Cieslak TJ, Rajnik M, Roscelli JD. Immunization against Haemophilus influenze type B fails to prevent orbital and facial cellulitis: Results of a 25-year study among military children. Military Med 2008;173:941-4.

17. Onakpoya $\mathrm{OH}$, Adeoye $\mathrm{AO}$, Akinpelu OV, et al. Cost-related antibiotic dosage omissions - challenge for orbital cellulitis management in resource poor communities. Orbit 2009;28:147-52.

18. Yang M, Quah BL, Seah LL, et al. Orbital cellulitis in children medical treatment versus surgical management. Orbit 2009;28:124-36.

19. Israele V, Nelson JD. Periorbital and orbital cellulitis. Pediatr Infect Dis J 1987;6:404-10.

20. Ryan JT, Preciado DA, Bauman N, et al. Management of pediatric orbital cellulitis in patients with radiographic findings of subperiosteal abscess. Otolaryngol Head Neck Surg 2009;140:907-11.

21. Garcia GH, Harris GJ. Criteria for nonsurgical management of subperiosteal abscess of the orbit. Ophthalmology 2000;107:1454-8.

22. Chaudhry IA, Shamsi FA, Elzaridi E, et al. Outcome of treated orbital cellulitis in a tertiary care centre in the Middle East. Ophthalmology 2007;114:345-54. 


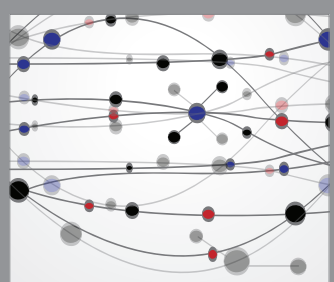

The Scientific World Journal
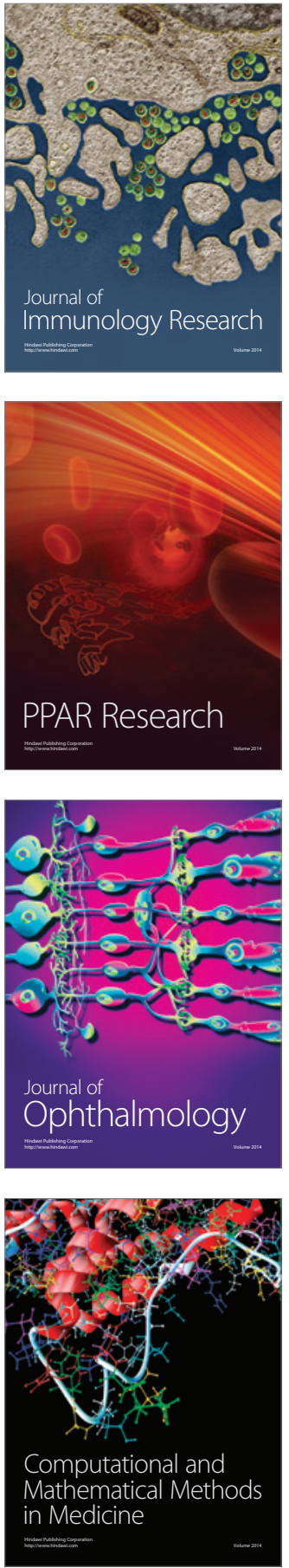

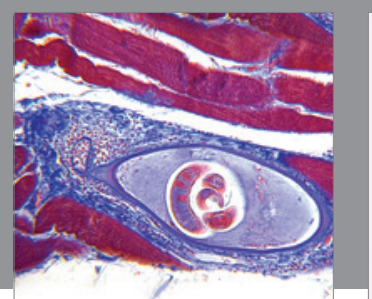

Gastroenterology Research and Practice

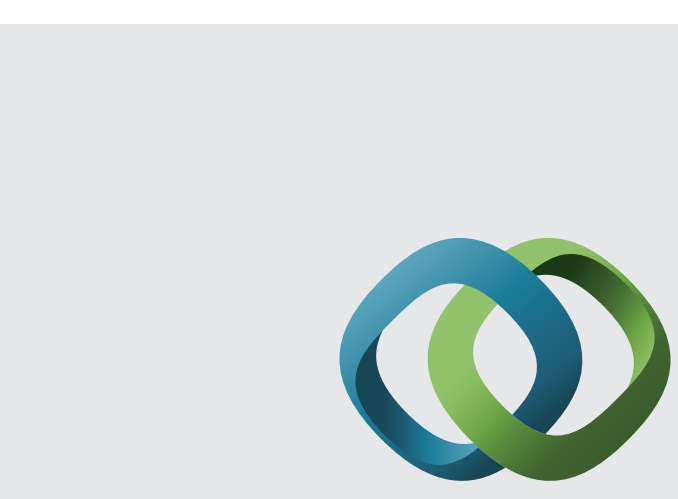

\section{Hindawi}

Submit your manuscripts at

http://www.hindawi.com
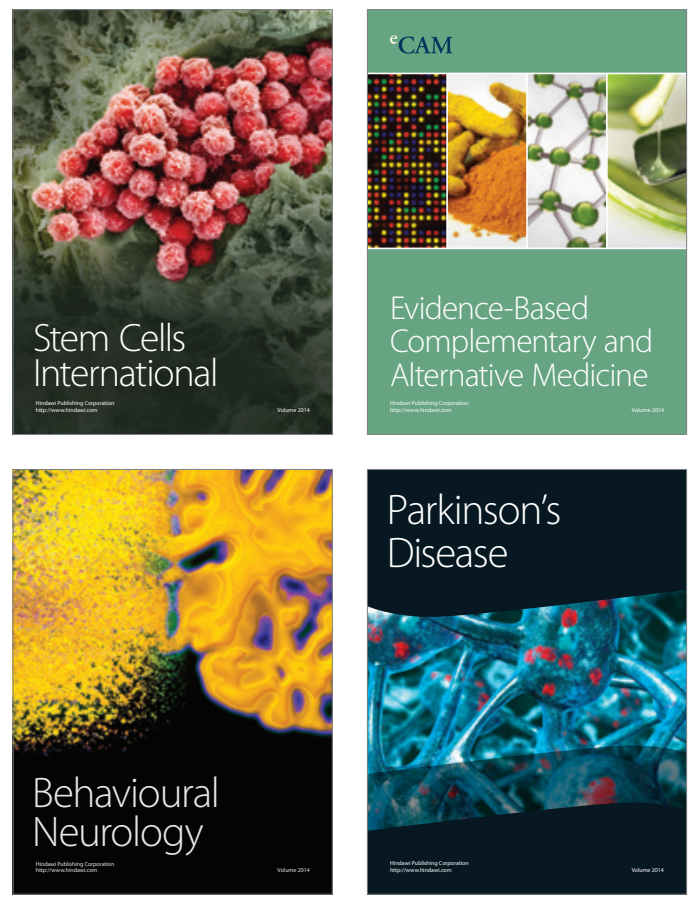
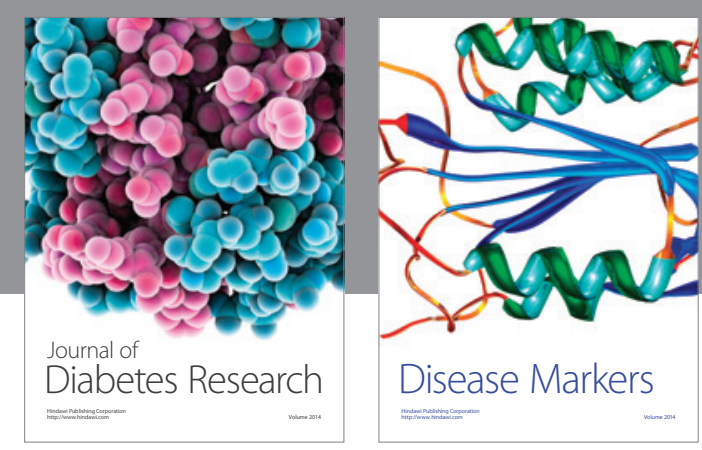

Disease Markers
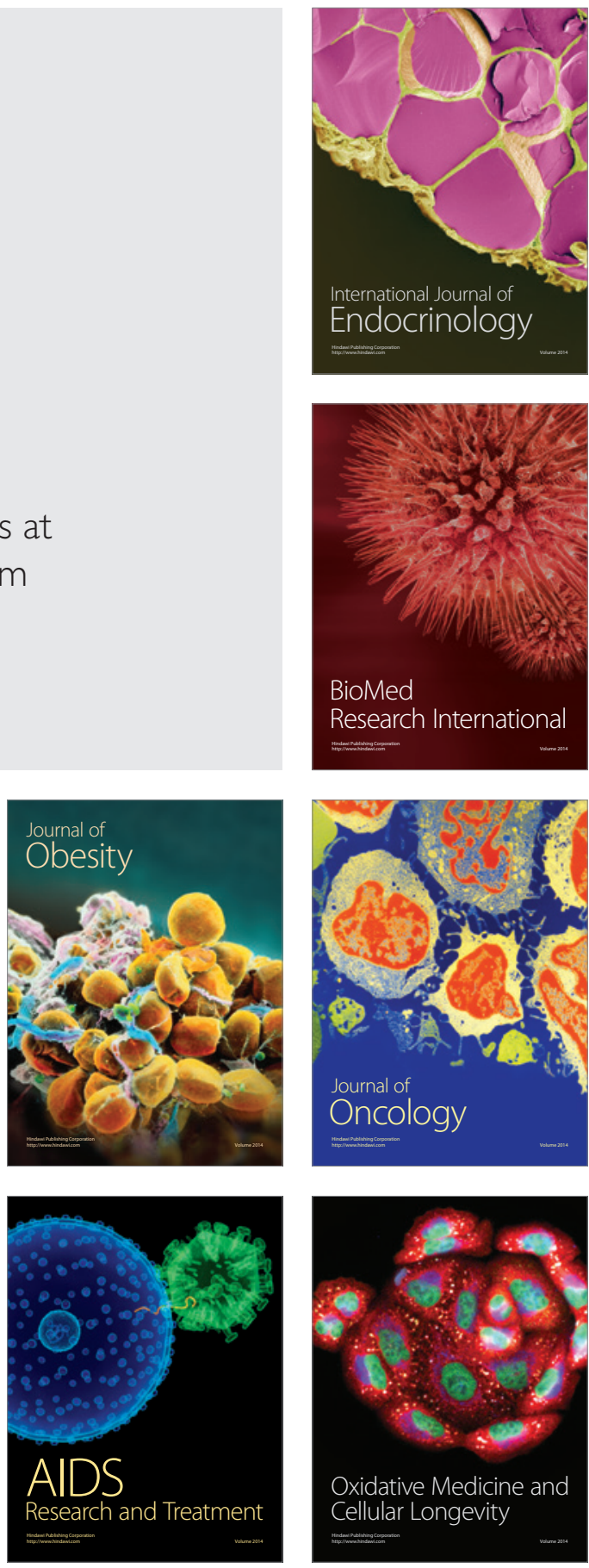